\title{
SIR/RSNA/CIRSE Joint Medical Simulation Task Force Strategic Plan: Executive Summary
}

\author{
Derek Gould · Aalpen Patel · Gary Becker · Buddy Connors · John Cardella • \\ Steven Dawson · Craig Glaiberman · David Kessel · Mick Lee · William Lewandowski • \\ Roger Phillips · Jim Reekers · David Sacks · Marc Sapoval · Mark Scerbo
}

Published online: 22 June 2007

(C) Springer Science+Business Media, LLC 2007

\section{Strategic Mission}

The Executive Councils of the Society of Interventional Radiology (SIR), Radiological Society of North America (RSNA), and Cardiovascular and Interventional Radiological Society of Europe (CIRSE) have charged their Medical Simulation Task Forces and Work Groups to cooperate to

This article also appears in the July 2007 issue of Journal of Vascular and Interventional Radiology.

\section{Gould ( ()}

Radiology Department, Royal Liverpool University Trust,

Liverpool, UK

e-mail: dgould@liv.ac.uk

\section{A. Patel}

Department of Radiology, University of Pennsylvania School of

Medicine, Philadelphia, PA 19104, USA

G. Becker

Department of Radiology, University of Arizona College of Medicine, Tucson, AZ, USA

B. Connors

Radiology Associates of Sacramento, Sacramento, CA, USA

J. Cardella

Department of Radiology, Baystate Health System/Tufts University School of Medicine, 759 Chestnut Street, C3162, Springfield, MA 01199, USA

\section{S. Dawson}

Department of Radiology, Massachusetts General Hospital, Harvard Medical School, Boston, MA, USA

\section{Glaiberman}

Mallinckrodt Institute of Radiology, Washington University School of Medicine, 510 South Kingshighway Boulevard, Box 8131, St. Louis, MO 63110, USA achieve excellence and safety in interventional radiology patient care by jointly recommending and guiding implementation of a robust infrastructure and process to support Interventional Radiology (IR) simulation development, assessment, validation, application, and dissemination.

The goal of medical training is to create practitioners who demonstrate mastery of the professionalism (skills, knowledge, attitudes, and behavior) required for the successful delivery of medical therapy [1]. A well-designed and fully integrated curriculum is the essential mechanism

D. Kessel

Leeds Teaching Hospitals, Leeds, UK

M. Lee

Department of Radiology, Beaumont Hospital, Royal College of Surgeons in Ireland, Dublin, Ireland

W. Lewandowski

William E. Lewandowski Consulting, Daytona Beach, FL, USA

R. Phillips

Department of Computer Science, University of Hull, Hull, UK

J. Reekers

Department of Radiology, Academic Medical Centre,

Amsterdam, The Netherlands

D. Sacks

Department of Radiology, The Reading Hospital and Medical Center, Reading, PA, USA

M. Sapoval

Department of Radiology, Hopital Europeen G, Pompidou, Paris, France

M. Scerbo

Department of Psychology, Old Dominion University, Norfolk, VA, USA 
by which this mastery is achieved. Since ancient times, mastery of the curriculum's clinical, cognitive, psychomotor, and attitudinal skills have been acquired in the master-apprentice training model (MAM). After initially observing the instructor, the trainee is eventually allowed "hands-on" experience under supervision: in the past this has been supplemented with training on physical and animal models, cadavers, and, more recently, analogue, digital, and hybrid simulation [2].

The limitations of the traditional MAM for learning in patients include the need for expert supervision, the potential for suboptimal results or harm, time constraints, rising costs, stress, ethical considerations, and an adversarial medicolegal milieu. In addition, diagnostic imaging advances have all but eliminated the need for the straightforward invasive diagnostic procedures which had been used to train basic skills in interventional radiology (IR). These difficulties have led to a reappraisal of alternative training methods for the 21 st century to augment and segmentally replace the traditional training methods.

Teaching models and tools must be cost effective, adaptable to change, and proven to develop skills that transfer to clinical circumstances. Where this gold standard validation proves elusive, these new medical simulators must be reconfigured to optimize the probability of validation. Medical simulation, using a combination of physical models and computer simulations, holds considerable promise for training, but to do this effectively requires accepted principles of educational methodology, including the need to obtain procedural skills within an overarching curriculum, with comprehension of the underlying condition and the risks and benefits of various therapies. Yet while standards exist for aviation, there are as yet none for the methodology and validity of medical simulations.

\section{Validation}

Public and professional acceptance of the use of simulation as a component of training high stakes IR skills requires proof (validation) of effectiveness. Validation of "testing" requires the ability to accurately assess knowledge and performance as they relate to learning objectives. The requirements for validating the use of a training device as a part of a curriculum depend on considerations such as the need

(1) to claim that participating in a particular training program is an accurate indicator of a level of competence or proficiency in the clinical environment;

(2) to claim that the use of a particular training device consistently provides particular results (proficiency, reduced training costs/errors over time), when used by different individuals in different training programs;
(3) to standardize a range of training programs to ensure that each predictably delivers a certain percentage of learners attaining predefined standards within a set period of time;

(4) for acceptance by users, experts, or other third parties (e.g., the public). This acceptance is generally more likely where training is performed with validated tools.

For these reasons, development of recommendations for validation and defined standards (including those specified within a curriculum) underpins the Joint Medical Simulation Task Force (JMST) strategic plan [3, 4].

\section{A Strategy for Implementation}

To safely implement simulator-based training in a curriculum requires evidence of clinical relevance, yet continued technology development might rapidly render well-conducted validation studies obsolete. It therefore seems prudent to adopt new technology for use within its areas of known efficacy [3] as determined by development history, metrics, validation studies, and the standards that are to be set in consequence of this strategy. Indeed clinically appropriate innovation, development, and instructional design should facilitate validation, opening up a new era in medical procedural training.

To increase the role of simulation in correctly teaching the cognitive and clinical knowledge necessary for the practice of IR requires thoughtful development and careful, yet expeditious, incorporation into official training curricula. This requirement has been identified by the Executive Councils of SIR and CIRSE and the Board of Directors of the RSNA [5]. The JSTF has been charged with recommending to their leadership a plan to integrate, throughout their divisional structures, the analysis, development, assessment, application, and dissemination of medical simulation in IR. This includes professional education, standards, research (principally direction, advice, and support), economics, practice building, and public information. The JSTF is not a credentialing body: its recommendations will include professional education, standards, research, economics, practice building, and public information. They will be derived from evidence-based and subject matter expert advice. The RSNA continues to work with SIR and CIRSE on the vision, mission, and goals for simulation in IR and beyond, as well as an implementation plan.

\section{The 2010 Vision of the Societies}

By 2010 a growing number of validated IR simulation training modules will (1) have been shown to transfer skills and reduce procedural error, (2) be delivering clinical 
benefit to patients, and (3) have been integrated into a standardized IR training curriculum and certifying examinations - the newly formed American Board of Radiology (ABR) Foundation is planning on a major role for simulation in its early initiatives.

\section{Specific Goals to Attain the Mission of the Joint Simulation Task Force}

1. To foster international relationships between societies and physicians in recognition of an increasingly global radiology community

2. To help the IR profession meet the anticipated growth in demand for interventional radiologists by conducting activities which, through introducing simulation into curricula, will help

a. To continuously improve education and training to reflect the current and evolving specialty of IR

b. To encourage and educate students at the undergraduate level

c. To meet the educational and continuing professional development needs of the societies' members

3. To become stronger and more inclusive societies by demonstrating leadership in key clinical and technology areas affecting the future of IR

4. To advocate successfully on behalf of patients

a. To ensure that they have access to optimal care

b. To provide excellence in that care by

i. Recommending standards in education

ii. Using medical simulation optimally to improve patient safety

5. To support and disseminate high-quality research in radiological sciences relevant to simulation and pursue excellence in publications and communications of this research

\section{Strategy Outline $[3,4]$}

This two-stage strategy aims to achieve the stated goals for medical simulation with specific reference to financial implications and expected timeframes. While not intended to be prescriptive, the societies recognize the pressing need for such an initiative in the field of IR simulation, recognizing that periodic updates and modifications will be needed to address evolving technology and political issues. The JSTF will work to develop the strategy objectives and disseminate findings collaborating with others as required to meet the societies' mission of excellence in IR patient care.
Stage I

Stage 1 comprises two parallel strands, curriculum development and organizational objectives.

\section{A. Curriculum development}

This defines the role of simulation within a structured, training program including how, where, and when simulator training takes place. It will also review assessment methodologies for establishing competence including traditional techniques, novel automatic assessment based on simulator-derived performance data, and observer-based methods. Finally, it outlines the role of credentialing organizations to oversee accreditation and revalidation

\section{B. Organizational objectives}

These consider how utilizing simulator models could improve the performance of IR training and of health care institutions. Human factors for the adoption of medical simulation standards will be determined, including identification of metrics and agreement on standards for the validity and efficacy of simulator models. Criteria for evaluating simulators will be developed with respect to learning, training, and the nature of performance feedback. Support for the task force will be enlisted from the industry, funding organizations, and the government. A program will be formulated for implementation of simulator-based training in IR curricula. Finally, recommendations will be made regarding the use of simulation by simulator and medical device companies for education, when operating outside curricula [6].

\section{Stage II}

It is intended that this strategy will provide guidance. Research methodology (i.e., milestones, Gantt charts, specifications, costings, personnel, etc.) is expected to be generated and implemented by various other groups. The core objectives of this stage are summarized below.

\section{A. Training standards}

\section{B. Professional education}

\section{Practice building}

\section{Research}

This part of the strategy aims to provide direction, advice, and support to researchers from within and outside the collaborative, academic, and industrial partners of the JSTF. 


\section{E. Economics}

\section{F. Public education}

\section{References}

1. Irvine D (2007) Medical Professionalism. Evidence from Sir Donald Irvine. Royal College of Physicians. Available at: http:// www.rcplondon.ac.uk/wp/medprof/medprof_prog_041216.asp; accessed 8 May

2. Dawson S (2006) Procedural simulation: a primer. J Vasc Interv Radiol 17(2; Pt 1):205-213
3. Cardiovascular and Interventional Radiology Society of Europe (2007) Available at: http://www.cirse.org/_files/ contentmanagement/CIRSE_SIR_Joint_Strategy.pdf; accessed 20 April

4. Society of Interventional Radiology (2007) Available at: http:// www.sirweb.org/clinical/cpg/CIRSE_SIR_Joint_Strategy_7-1406.pdf; accessed 1 May

5. Gould DA, Reekers JA, Kessel DO, et al. (2006) Simulation devices in interventional radiology: caveat emptor. CardioVasc Interv Radiol 29(1):4-6

6. Morgan JM, Marco J, Stockx L, et al. (2005) Educational governance for the regulation of industry sponsored continuing medical education in interventional and device based therapies. Heart 91:710-712 